ARCHIVO ESPAÑOL DE ARTE, LXXXVI, 344

OCTUBRE-DICIEMBRE 2013, pp. 331-344

ISSN: 0004-0428

\title{
NUEVOS DATOS EN TORNO AL ESCULTOR JOSEP BOVER I MAS (1802-1866)
}

\author{
CRISTINA RodRíguez SAMANIEGO \\ Universidad de Barcelona
}

\begin{abstract}
Josep Bover i Mas (1802-1866) fue uno de los más destacados escultores españoles de la Academia de Bellas Artes de Barcelona de la primera mitad del siglo XIX, desarrollando una interesante carrera como creador profesional y docente que, hasta el día de hoy sólo ha sido estudiada de forma fragmentaria. El presente artículo pretende reunir la escasa bibliografía publicada en torno al escultor y aportar numerosos datos nuevos relacionados con su vida y obra, facilitando la interpretación global de su trabajo. Asimismo, pretende sugerir una reflexión sobre la escultura académica decimonónica con el objetivo de contribuir a renovar la visión que de ésta se ha presentado hasta el momento.

Palabras clave: Josep Bover; escultura; academicismo; Barcelona; Academia de Bellas Artes de San Jordi; siglo XIX.
\end{abstract}

\section{NEW DATA CONCERNING THE SCULPTOR JOSEP BOVER I MAS, 1802-1866}

Josep Bover i Mas (1802-1866) was one of the most distinguished Spanish sculptors of the Academy of Fine Arts of Barcelona during the first half of the $19^{\text {th }}$ century. He had a major career as professional artist and teacher, which has been only partially studied. The author here assembles the scarce bibliographical information available on this sculptor and presents new data relating to his life and production, in order to provide a comprehensive interpretation of his works. Likewise, a renewed reflection on Spanish $19^{\text {th }}$-century academic sculpture is proposed.

Key words: Josep Bover; sculpture; academic art; Barcelona; Academy of Fine Arts of Barcelona; 19th century.

La bibliografía actual relativa a Josep Bover i Mas es exigua y fragmentaria, basada por lo general en la información que de éste se dio en los diccionarios biográficos de artistas publicados en España durante la segunda mitad del siglo XIX y la primera del XX. A día de hoy, no existe ninguna monografía o artículo especializado dedicado íntegramente al escultor. Ade-

\footnotetext{
${ }^{1}$ Este artículo es fruto de una investigación efectuada en el marco del Subprograma Juan de la Cierva (MICINN) y también ha recibido el apoyo del Grupo de Investigación GRACMON, Universidad de Barcelona (HAR2010-16328 Subprograma HIST). Esta investigación no habría podido dar frutos sin la inestimable colaboración de las Sras. $\mathrm{M}^{\mathrm{a}}$ Victoria Durá y Begoña Forteza, de la Reial Acadèmia de Belles Arts de Sant Jordi, Barcelona.
} 


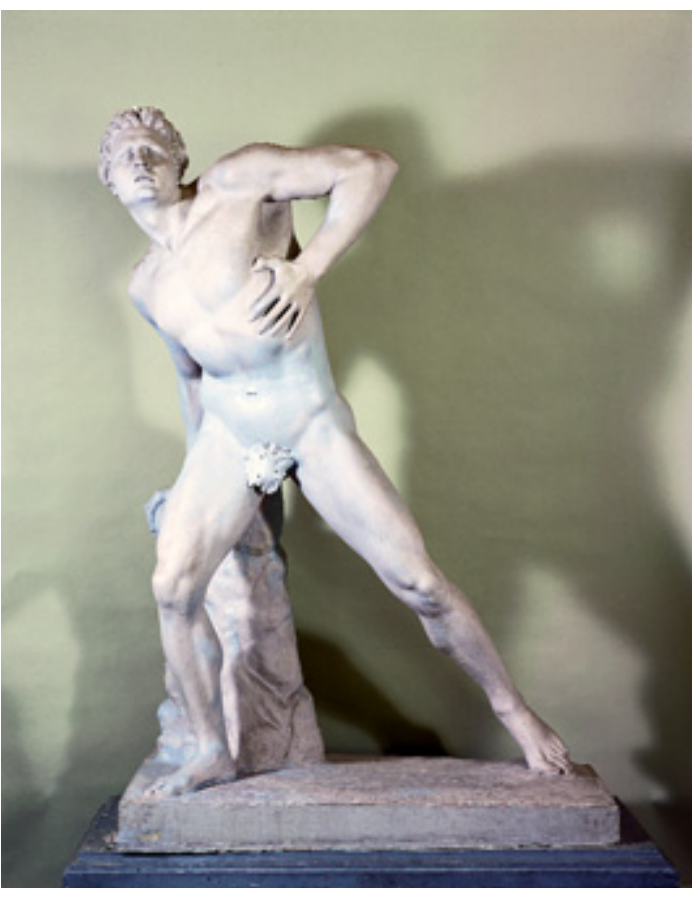

Fig. 1. Josep Bover, Gladiador herido, 1825, Barcelona, Museu de Llotja. (C) Reial Academia Catalana de Belles Arts de Sant Jordi.

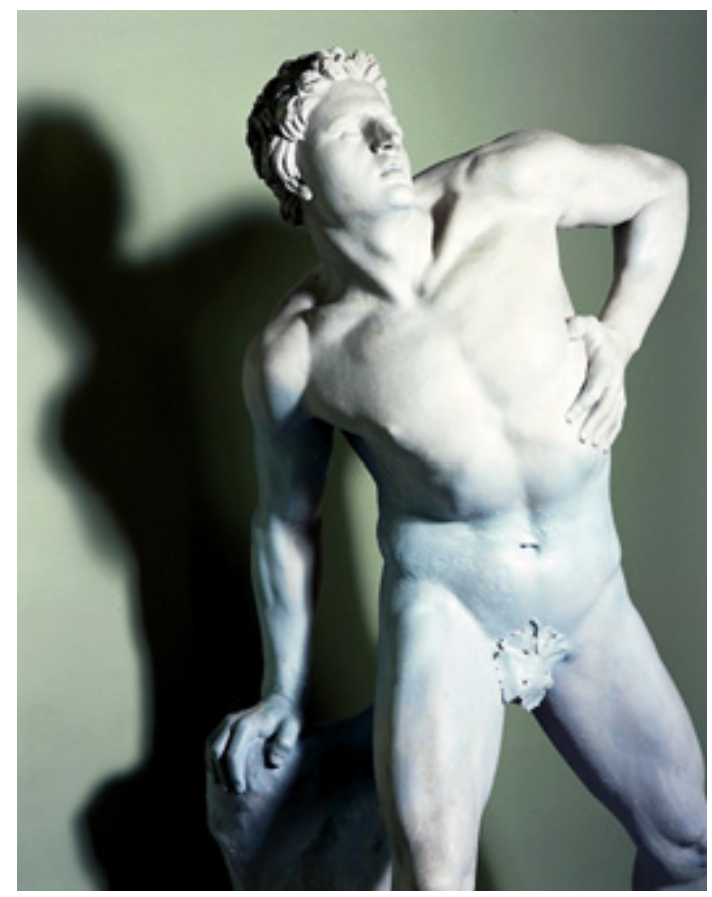

Fig. 2. Josep Bover, Gladiador herido, detalle.

más, salvo en contadas ocasiones, las referencias bibliográficas a Bover no están exentas de lagunas, imprecisiones y algunos errores, una situación que este artículo pretende remediar. Precisamente, ya los primeros comentarios a la obra del escultor catalán, aparecidos en $1850^{2}$, atribuían dos de sus obras más célebres, el Gladiador herido y el Gladiador vencedor, a Ramon Bover. La confusión en torno al nombre de pila del escultor se repitió en otras fuentes que se ocupaban de las mencionadas estatuas, como se ha ya señalado ${ }^{3}$. Hay también cierto desconcierto en lo tocante a su fecha de nacimiento y a la cronología de sus obras y hechos vitales, un problema que trataremos aquí de subsanar. El presente artículo se ocupa también de analizar la adscripción estilística del autor, un tema que ha sido objeto de una infructuosa discusión por parte de los especialistas en escultura decimonónica, resultando Bover calificado tanto de realista, neoclásico o, incluso, romántico. Añadiremos también que este texto profundiza en su intensa labor docente, desarrollada durante más de veinte años y que no ha sido tratada hasta el momento; siendo ésta una de las carencias que más notablemente han motivado el artículo que iniciamos a continuación.

\footnotetext{
${ }^{2}$ MAdOZ, 1850: 531.

3 Alternando entre la identificación del escultor con su hermano Ramón y con su padre, el también escultor y profesor académico Francesc Bover. VÉLEZ, 2001: 30-31. En concreto, la autora se refería a SAURí/MATAS, 1849: 187; ELIAS DE MoLINS, 1889: 320; y GAYA NuÑo, 1958: 99; referencias entre las que debería incluirse a Ossorio y BERNARd, 1868: 90. Añadiremos que, de forma puntual, también se han atribuido erróneamente obras de Francesc Bover a su hijo José, véase ELIAS, 1928:37.
} 


\section{Algunos datos biográficos y juventud del escultor}

Desafortunadamente, la destrucción de los registros municipales de bautismo de Barcelona anteriores a 1918 no nos permite asegurar con exactitud en qué año nació Josep Bover. Sin embargo, todo parece indicar que lo hizo en Barcelona alrededor de 1802 como sugirió Vélez ${ }^{4}$, si bien la mayoría de las fuentes se decantan por fechas anteriores al cambio de siglo. Las más tempranas sitúan el nacimiento del escultor en $1770^{5}$ o hacia $1790^{6}$, fechas que parecen poco plausibles atendiendo al desarrollo posterior de su carrera. Sin embargo, sí podemos afirmar con seguridad que éste murió en la Ciudad Condal en agosto de $1866^{7}$.

Josep Bover siguió los pasos profesionales de su padre, el también escultor Francesc Bover, quien trabajó como profesor de la Escuela de Nobles Artes de Barcelona desde su nombramiento como Teniente de director en $1797^{8}$ hasta su defunción, acaecida en la capital catalana antes del último trimestre de 1831 , habiendo superado los sesenta años de edad ${ }^{9}$. Poco se sabe hoy de la producción de Francesc Bover, más que su participación en la decoración escultórica del patio interior del edificio de la Escuela en 1802, con dos estatuas representando los continentes de Asia y Europa ${ }^{10}$. Debemos rescatar del olvido, además, el Retrato de Nicolás de Azara, busto en mármol obra del escultor, que figuraba en las colecciones de la Junta Particular de Comercio de Barcelona en $1847^{11}$. Pese a su poca relevancia en el contexto historiográfico actual, Francesc Bover debe ser recordado por formar parte del grupo de seis jóvenes artistas que recibieron la primera pensión a Roma de la mencionada Junta barcelonesa en el concurso de 1789-1790 ${ }^{12}$. Desempeñó, a su regreso de Italia, la dirección de la clase de Dibujo de perfiles y sombras, teniendo bajo su responsabilidad a dos maestros subalternos; además de encargarse interinamente de la dirección de la clase de Principios de dibujo a finales de la década de $1820^{13} \mathrm{y}$ de substituir a Damià Campeny (1771-1855) durante sus ausencias a partir de $1819^{14}$. Fue nombrado Académico de mérito de la Real Academia de San Carlos de Valencia, por la escultura, en setiembre de $1799^{15}$, pero nunca obtuvo el nombramiento

${ }^{4}$ Vélez, 2001: 30-32. Gaya Nuño situó su nacimiento entre 1800 y 1802. Véase GaYa NuÑo, 1958: 99.

${ }^{5}$ RÀFOLS, 1951: 160-161.

${ }^{6}$ SuBIRACHS, 1994: 91. En la página 70 del mismo libro, la autora indicaba que el escultor nació en 1802, sin corregir la anterior ni determinar cuál de ellas era la correcta a su parecer. También situaba su nacimiento hacia 1790 Art Públic de Barcelona, 2009: 523.

${ }^{7} \mathrm{Su}$ fallecimiento tuvo lugar antes del día 28. Véase La Correspondencia de España. Diario Universal de noticias, 28-VIII-1866: 2

${ }^{8}$ El nombramiento tuvo lugar el 7 de diciembre de 1797. Véase Memòries de diverses escoles amb nomenaments de professors, pressupostos de despeses, $i$ altres indicacions, Biblioteca Nacional de Catalunya (BNC), Barcelona, Arxiu de la Junta de Comerç, Caja 140, Legajo CVI, Libro 1, exp. 40. Se desconoce el segundo apellido del escultor.

${ }^{9}$ Convencionalmente, se indica el 1769 como fecha del nacimiento del escultor en Santa María de Corbera (provincia de Barcelona) aunque, también en este caso, hay discrepancias. Algún autor apunta a 1765, véase RierA, 1994: 179-181. En cuanto a la fecha de su defunción, sabemos que ya no impartió docencia en el curso 1831-1832. Véase Arxiu de la Reial Academia Catalana de Belles Arts de Sant Jordi (RACBASJ), Barcelona, caja Junta Comerç. Comunicacions 18151849, Mns. 154.

${ }^{10}$ Ambas obras en mármol, de idénticas proporciones: 200 x 100 x $75 \mathrm{~cm}$. Se hallan actualmente en su emplazamiento original. Completan el conjunto América y África, de Manuel Olivé, de iguales materiales y dimensiones.

${ }^{11}$ El retratado fue, desde 1785 hasta 1798, embajador de España en Roma, donde pudo Bover llegar a conocerle. Véase Real Junta de Comercio de Cataluña: 1847, n. 9.

${ }^{12}$ Concurso resuelto el 14 de julio de 1790. Véase Cartes rebudes sobre assumptes diversos: drets duaners, gremis, consolats, escoles, pensionats, etc, BNC, Arxiu de la Junta de Comerç, Caja 42, Legajo XXIX, Libro 1, exp. 351-353.

${ }^{13}$ RACBASJ, caja Junta Comerç. Comunicacions 1815-1849, Mns 44, 81, 145, 151 y 154.

${ }^{14}$ Registro de Oficios de 1816 a 1837 en orden cronológico (y al final otras listas de 1815 a 30 y de 1824 a 1832 fechas no continuas), RACBASJ, n. 39.

15 OsSORIO y Bernard, 1868: 90.

Arch. esp. arte, LXXXVI, 344, octUBRE-DICIEMBRE 2013, 331-344, ISSN: 0004-0428 


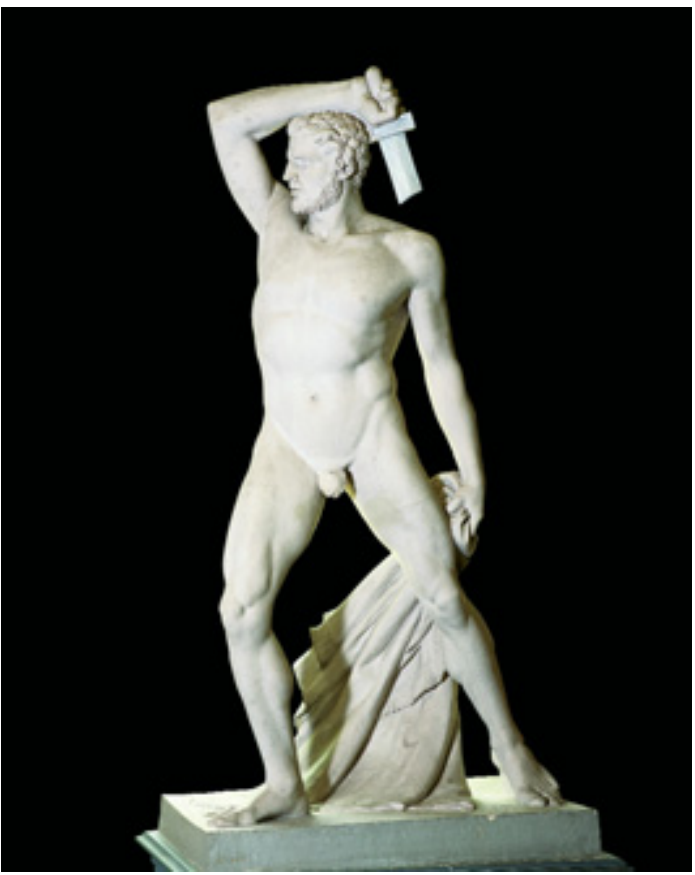

Fig. 3. Josep Bover, Gladiador vencedor, 1825, Barcelona, Museu de Llotja. (C) Reial Academia Catalana de Belles Arts de Sant Jordi.

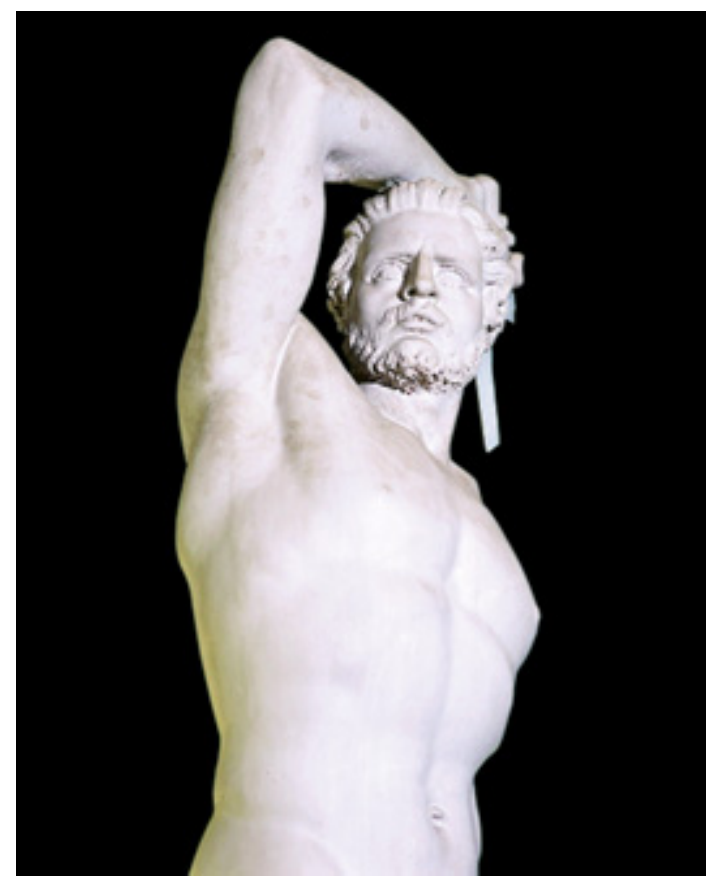

Fig. 4. Josep Bover, Gladiador vencedor, detalle.

de la de San Fernando de Madrid ${ }^{16}$. Parece ser que Josep Bover fue su primogénito y, además, Francesc tuvo a otro hijo varón más, Salvador, quien estuvo también vinculado a la Escuela y a la práctica de la escultura ${ }^{17}$. Algunas fuentes afirman la existencia de un tercer hijo, Marià, si bien nuestra investigación ha desvelado que lo más probable es que no fuera hermano carnal de Josep ${ }^{18}$.

Josep Bover i Mas empezó a cursar sus estudios en la Escuela de Nobles Artes, entonces dependiente de la Junta de Comercio de Barcelona, en el curso 1817-1818 ${ }^{19}$. Más tarde, entre 1820 y 1823 , se presentó como concurrente a los premios trimestrales y extraordinarios de la Escuela en varias ocasiones. Los premios a los que optaba pertenecían a la disciplina escultórica y al dibujo, destacando

${ }^{16}$ RIERA, 1994: 289.

${ }^{17}$ Salvador Bover se presentó a los premios trimestrales de la Escuela de Nobles Artes en 1820, 1821 y 1822 en la modalidad de Modelo de yeso en escultura, sin demasiado éxito. En las listas de concurrentes a los concursos, se especificaba que Francesc Bover no votaría "por ser padre del opositor". Véase Lista de los opositores que concurren á la oposicion de los premios del trimestre... RACBASJ, caja 313. Reial Junta Comerç Escola de Nobles Arts. Premis - alumnes. 1787-1835.

${ }^{18}$ RiERA, 1994: 180, afirma que Francesc tuvo un hermano y un hijo con dicho nombre de pila. Lo cierto es que un tal Marià Bover i Rubí se presentó a los premios trimestrales de la Escuela entre 1825 y 1828, obteniendo gratificaciones en Figuras copiadas de diseño y en Modelo de yeso en diseño. Además, en las listas de opositores aparece también el nombre de Francesc Bover i Rubí, presentándose a Figuras de Estampa y a Flores y adornos. El lazo carnal con Francesc Bover sénior se hace evidente al abstenerse éste de votar en dichas ocasiones. Probablemente se trate de los hijos de su hermano, por lo tanto, primos de Josep y Salvador, aunque no podemos descartar que se trate de hijos de un segundo matrimonio del escultor. No hemos conseguido hallar más información relativa a estas personas. Véase Lista de los opositores que concurren á la oposición..., RACBASJ, caja 313. Reial Junta Comerç Escola de Nobles Arts. Premis - alumnes. 1787-1835. 
los de las especialidades de Modelo en yeso en escultura, Modelo natural en escultura y Oficios y artefactos. Obtuvo recompensas de segunda y tercera clase en los dos últimos ${ }^{20}$, unas gratificaciones que le auguraban ya un futuro prometedor como artista. Sin embargo, para que su formación pudiera ser considerada completa, éste debía realizar la consabida estancia en Roma. Nuestra investigación permite demostrar que la fecha en la que se había situado la partida de Bover hacia Roma, $1825^{21}$, no es correcta y debe emplazarse al menos un año antes. Las dificultades en la localización temporal de su estancia italiana son debidas principalmente al hecho que Bover no recibió pensión oficial de la Junta de Comercio barcelonesa. De hecho, se estableció en Italia por su cuenta, con los medios que le proporcionó su familia. Los documentos que hemos consultado así lo demuestran; es más, nos permiten añadir que en enero de 1824, al cabo de un tiempo de estar Josep en Roma, Francesc Bover pidió a la Junta que se encargara de gestionar el pago de las mensualidades a su hijo, que se deducirían de su sueldo ${ }^{22}$. En concreto, éstas constituirían la mitad de sus honorarios, y de la otra mitad se obtendrían los gastos de cambio de divisa; una situación sin duda gravosa para su familia, que tuvo que considerar imprescindible esta estancia para el desarrollo de su carrera. No debe extrañarnos el que Bover no obtuviera pensión oficial. De hecho, 1823 fue convulso, con el fin del Trienio liberal y la reposición en el trono de Fernando VII, situación que dificultó la financiación de las escuelas de la Junta de Comercio y de sus pensionados, siendo el pintor Segimon Ribó i Mir enviado a Roma aquel año gracias a la aportación de un particular del mundo del comercio ${ }^{23}$.

Josep Bover se habría instalado en el país transalpino en el decurso del año 1823. En marzo de 1824 el embajador de España en Italia, Antonio de Vargas Laguna, indicaba en su correspondencia haber recibido la visita del joven escultor en Roma ${ }^{24}$. Asimismo, también en marzo de ese año, el propio Bover escribió al presidente de la Junta de Comercio, Pau Fèlix Gassó, agradeciéndole la ayuda prestada con motivo de su viaje ${ }^{25}$. En Roma, el escultor percibía una asignación de doce duros mensuales, de cuyo pago se ocupaba el eclesiástico Manuel Ximeno de la Riva ${ }^{26}$. A mediados de 1827, un año antes de la fecha que se indica habitualmente, Josep Bover habría vuelto ya a Barcelona, y se estaría preparando para desempañar su carrera profesional al amparo de la Junta y de la Escuela de Nobles Artes ${ }^{27}$.

${ }^{19}$ A setiembre de 1817 pertenece la primera mención de su nombre que aparece en los libros de matrículas. Véase Libro num.1. Que da razón de los discípulos matriculados en la Escuela Gratuita de Dibujo establecida en la real casa Lonja de la Ciudad de Barcelona a espensas de la Real Junta Particular de Comercio de Cataluña, la qual dió principio el dia 23 de Enero de 1775, RACBASJ. Anna Riera había apuntado que Bover se habría matriculado en la escuela en 1814, indicando la fuente documental que le permitía hacer dicha afirmación. Sin embargo, esta fuente se ha revelado ser inexacta o estar equivocada. Véase RIERA, 1994: 140.

${ }^{20}$ Lista de los opositores que concurren á la oposicion de los premios del trimestre..., RACBASJ, caja 313. Reial Junta Comerç Escola de Nobles Arts. Premis - alumnes. 1787-1835.

${ }^{21}$ Subirachs, 1994: 89.

${ }^{22}$ Véase Llibre d'acords 1824, 19-I-1824, BCN, Arxiu de la Junta de Comerç, JC 39, p.16, anverso. Judit Subirachs había ya apuntado que Francesc Bover renunció a una parte del sueldo para cubrir los gastos de la estancia de su hijo en Roma, aunque no daba más datos ni indicaba justificación documental alguna. SuBIRACHS, 94:70.

${ }^{23}$ Véase Llibre d'acords 1823, 26-VI-1823, BCN, Arxiu de la Junta de Comerç, JC 38, p.78. Esta situación se hacía extensible a otras zonas del Estado. La Real Academia de San Fernando de Madrid, por ejemplo, no distribuyó Premios de Roma entre 1800 y 1830.

${ }^{24}$ Carta de Antonio de Vargas a Felip Amat, BNC, Arxiu de la Junta de Comerç, legajo XLVIII, caja 64, exp. 343.

${ }^{25}$ Carta de Josep Bover a P. Fèlix Gassó, 6 de marzo de 1824, BNC, Arxiu de la Junta de Comerç, legajo XLVIII, caja 64, exp. 445. La carta fue más tarde mencionada en reunión de Junta. Véase Llibre d'acords 1824, 2-IV-1824, BCN, Arxiu de la Junta de Comerç, JC 39, p. 55 anverso.

${ }^{26}$ Quien, a su vez, también gestionaba las mensualidades dadas a los pensionados. Carta de Nicolás Ponte a P. Fèlix Gassó, 4 de mayo de 1825, BNC, Arxiu de la Junta de Comerç, legajo XLVIII, caja 64, exp.386. Esta asignación era la mitad que la que percibía Segimon Ribó. Ver nota 23 del presente artículo.

27 Véase BNC, Arxiu de la Junta de Comerç, legajo LXXXV, caja 115, exp. 398. 


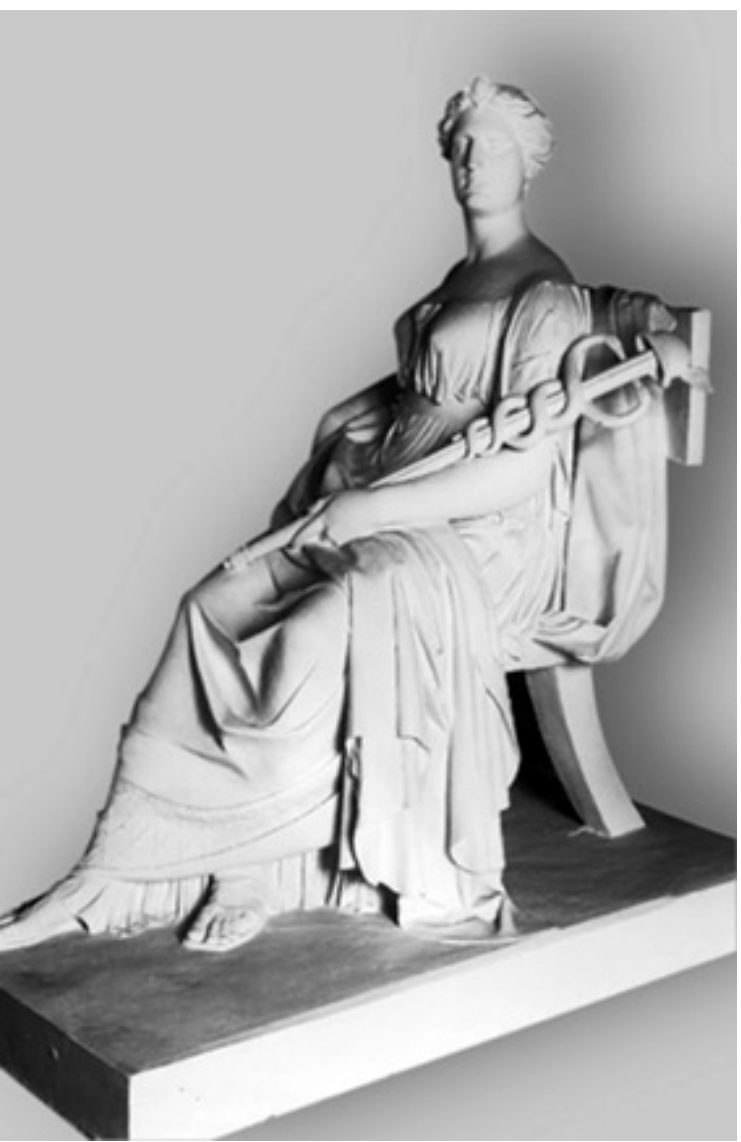

Fig. 5. Josep Bover, La Junta de Comercio, yeso, ca 1838-1846. Barcelona, Museu de Llotja. (C) Reial Academia Catalana de Belles Arts de Sant Jordi.
De los detalles diarios de la estancia en Roma de Josep Bover se sabe muy poco. Probablemente cumplió con las obligaciones de cualquier pensionado por la escultura en la ciudad, ocupándose en las clases y envíos de obras a España ${ }^{28}$. De esta época son las mencionadas Gladiador herido y Gladiador vencedor, dos esculturas en yeso de tamaño mayor que el natural relacionadas entre ellas por su tema, aunque con diferencias estilísticas notables. Pardo Canalís sugirió que sólo el Gladiador herido habría sido realizado en Italia, mientras que la segunda obra se hubiera podido crear al regresar el escultor a Barcelona, con el objetivo de acallar las voces que insinuaban que él no era el autor de la primera $^{29}$. La documentación que hemos consultado permite confirmar que dicha obra fue realizada en Roma ${ }^{30}$, aunque no hemos hallado indicación alguna del lugar de creación del Gladiador vencedor. Se trata de las obras más tempranas que se conocen del autor y aparecen en las descripciones e inventarios del Museo de la Junta de Comercio desde $1826^{31}$.

Se han señalado ya las concomitancias de dichas obras con otras ejecutadas poco tiempo antes en Roma por el italiano Antonio Canova y el cordobés José Álvarez Cubero $(1768-1827)^{32}$. De hecho, el espíritu clásico de Cubero y su fluidez en la descripción anatómica se hacen patentes en las dos composiciones de juventud del catalán. Nuestra investigación permite confirmar, además, que el andaluz habría acogido a Bover en su taller como discípulo, protegiéndolo y ejerciendo

${ }^{28}$ Para más detalles sobre las obligaciones de los pensionados españoles en Roma por la escultura en torno a 1800, véase la magnífica tesis de Azcue, 2002 (1991): 148-228; y las referencias específicas a los pensionados de la Junta, en RIERA, 1994: 345-346 ó Alonso, 1976: 97-99.

${ }^{29}$ PARDo, 1958: 29.

${ }^{30}$ En una carta de 1856, en la que el escultor pedía permiso a la Academia para que se efectuara el vaciado en yeso del Gladiado herido, éste especificaba que dicha obra había sido realizada en Roma. Véase RACBASJ, caja 23. Acadèmia de Belles Arts. Sección de Escultura. Dictámenes 1850-1870, exp. 105 y nota 75 del presente artículo.

${ }^{31}$ Gladiador herido, 200 × 134 × $81 \mathrm{~cm}, 1825$, número de inventario 0366E y Gladiador vencedor, 260 × 84 × 132 cm., 1825, número de inventario 0354E, Museu de Llotja, RACBASJ. Véase Nota de lo que ha aumentado la Escuela desde 1814 hasta el presente, RACBASJ, caja 4-6.

32 Fontbona, 1983: 48. GaYA Nuño, 1958:75. Por otra parte, Christiane Dotal hizo alusión a la influencia sobre Bover de Néstor y Antíoco de Álvarez, realizado en 1818, y en el que se basó su Defensa de Zaragoza (mármol, 150 x 200 cm, 1825, número de catálogo E789, Museo del Prado, Madrid), y el Gladiador vencedor de Bover (al que Dotal se refiere como Gladiateur Romain). DotaL, 2006. 
un patronazgo sobre su producción del momento ${ }^{33}$. Sirva este artículo también para apuntar otro paralelismo, inédito, entre La Junta de Comercio de Bover y algunas esculturas sedentes de Álvarez Cubero, como María Luisa de Parma ${ }^{34}$ de 1816 e Isabel de Braganza ${ }^{35}$, realizada entre 1826 y 1827 , cuando el escultor se hallaba ya en España. La tipología usada por Cubero es el claro referente en esta obra de Bover. Las similitudes son fáciles de apreciar en lo formal, sobre todo en cuanto a la postura corporal y el trabajo de ropajes se refiere. Se cree que Bover dio forma a La Junta de Comercio a finales de la década de 1830 o principios de la de $1840^{36}$ aunque, por todo lo apuntado aquí, opinamos que se podría proponer una fecha anterior para esta obra, más próxima a su estancia en Roma cerca del maestro cordobés. Añadiremos a las semejanzas expuestas las que apreciamos entre el Gladiador vencedor y ciertas obras de Antoni Solà (1780-1861), como La matanza de los Inocentes; y entre El Gladiador herido y Orestes atormentado por las Furias ${ }^{37}$, enviadas a Barcelona durante la pensión de su autor en Roma y que Bover sin duda conocería de su etapa formativa en la escuela de la Junta.

\section{Revisión de la producción de Josep Bover}

Los gladiadores han sido entendidos por algunos historiadores del arte como un punto de inflexión en la carrera del escultor y presentados, consecuentemente, como muestra de su evolución hacia el romanticismo desde un neoclasicismo de cariz académico ${ }^{38}$. A nuestro parecer, este análisis es correcto pese a ser reduccionista. La inspiración clásica de las obras es evidente, y va más allá de lo meramente temático, pero ciertos detalles formales de éstas se escapan del estilo repetitivo, vacío perpetuador de patrones, al que solemos referirnos cuando hablamos de academicismo en la escultura española del XIX. En el Gladiador herido se aprecia lo apuntado con mayor facilidad que en el Gladiador vencedor, siendo la primera una pieza ya permeable a los corrientes románticos que empezaban a tomar forma en Europa por aquel entonces. Tanto el movimiento del cuerpo y su elasticidad, como el trabajo del rostro y su emotividad subrayan su evolución, que se hará patente en obras posteriores del escultor. Los retratos de la reina María Cristina y del rey Fernando VII, ejecutados en 1834 y 1835 respectivamente $^{39}$, muestran con claridad este progreso hacia una estética más naturalista, a la vez que sugieren un trasfondo psicológico de los personajes representados. Si bien dichos retratos han sido ya tratados por distintas fuentes ${ }^{40}$, podemos aportar como novedad algunos datos en torno a la demora en su realización, debida, además de a problemas arancelarios ${ }^{41}$, también a temas de presupuesto ${ }^{42}$.

${ }_{33} \mathrm{Tal}$ como se aclaró en un artículo sobre el escultor aparecido poco tiempo antes de su fallecimiento. Véase $L a$ Iberia, 22-VI-1860: s.p. Queremos añadir que Leticia Azcue mencionó, sin dar ningún detalle al respecto, que Bover era “alumno" de Álvarez. Azcue, 2002 (1991): 98. Lo mismo sucede en la tesis de Esther García. García, 2007: 20 (apéndice). Pardo Canalís apuntaba que los dos escultores fueron, incluso, amigos. PArdo, 1958: 29.

${ }^{34}$ María Luisa de Parma, mármol, 140 × 75 × $80 \mathrm{~cm}$, número de catálogo E902, en depósito en el Palacio Real de Madrid.

${ }^{35}$ La Junta de Comercio, yeso, 155 x 118 x $146 \mathrm{~cm}$, fecha desconocida (aprox. entre 1838-1846), número de inventario A-376, Museu de Llotja, RACBASJ. Isabel de Braganza, mármol de Italia, 145 x 102 x 145 cm, 1826-1827, número de catálogo E00001, Museo del Prado, Madrid.

36 VÉLEZ, 1994: 31.

${ }^{37}$ La matanza de los Inocentes, mármol, 158 x 90 x 97 cm, 1834 y Orestes atormentado por las Furias, yeso, 215 x 124 x $62 \mathrm{~cm}$, c.1810, números de inventario 0194E y 0367E, Museu de Llotja, RACBASJ.

${ }^{38}$ Subirachs, 1994: 45. Benet, 1958: 256.

39 Retrato de la reina María Cristina, mármol, 66 x 61 x 31 cm, 1834 y Retrato del rey Fernando VII, mármol, 61 x 61 x $31 \mathrm{~cm}, 1835$. Museu de Llotja, RACBASJ, números de inventario 0268E y 0264E.

${ }^{40}$ VÉLEZ, 2001: 31. SubirachS, 1994: 91.

${ }^{41}$ Como ya indicara CID, 1998: 127.

${ }^{42}$ En concreto, el escultor pide a la Junta que se le avancen 2000 reales de vellón para poder acabarlas. El importe fue deducido de la factura final del proyecto, acabado antes de mayo de 1835. Véase BNC, Arxiu de la Junta de Comerç, legajo XCV, caja 127 , n. 6, exp..23 y 28 . 


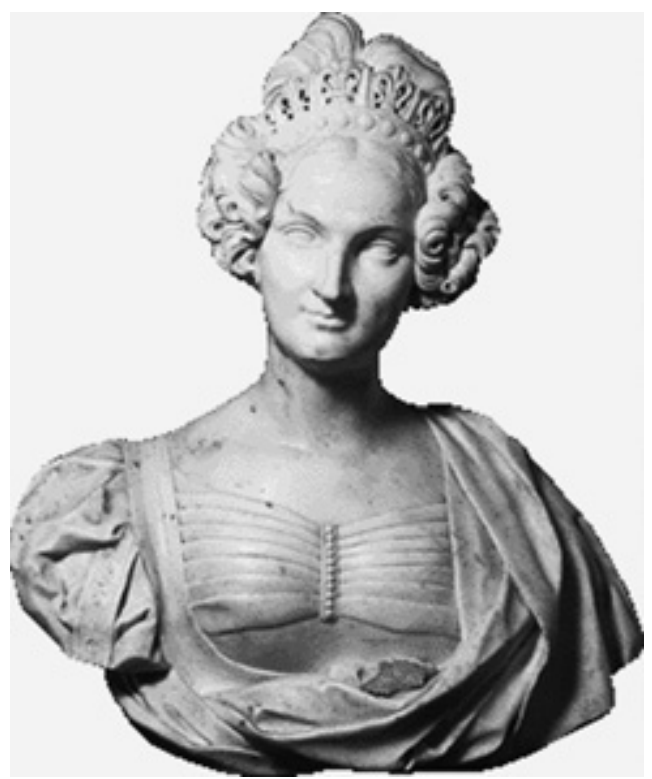

Fig. 6. Josep Bover, Retrato de la reina María Cristina, mármol, 1834, Barcelona, Museu de Llotja. (C) Reial Academia Catalana de Belles Arts de Sant Jordi.

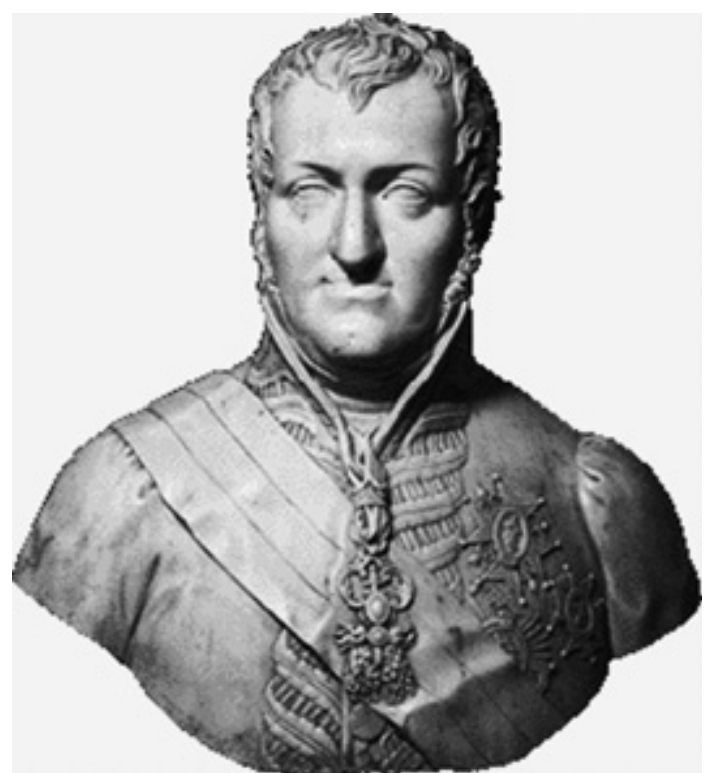

Fig. 7. Josep Bover, Retrato del rey Fernando VII, mármol, 1835, Barcelona, Museu de Llotja. (C) Reial Academia Catalana de Belles Arts de Sant Jordi.

Las estatuas Jaume I el Conquistador y Joan Fiveller, Conseller II de Barcelona, de mediados de la década de 1840, ambas en sendas hornacinas de la fachada principal del Ayuntamiento de Barcelona ${ }^{43}$, constituyen otro ejemplo de la evolución estilística en la obra de Josep Bover. En razón de su emplazamiento, son éstas sus dos composiciones más conocidas y han sido objeto de análisis muy dispares que, por supuesto, no contribuyen a la comprensión de la producción del escultor. En general, se las considera paradigmáticas del romanticismo escultórico, al tratarse de un tema histórico vinculado con el pasado nacional de Cataluña ${ }^{44}$. No obstante, la asociación de estas obras con el romanticismo no sólo se debe a su tema-impuesto por el propio encargo-, sino que es apreciable en su juego de volúmenes y movimiento, gracias a los cuales se alejó Bover del estatismo típico de lo neoclásico. Su relación con el nazarenismo, apreciada ya por Francesc Fontbona ${ }^{45}$, nos parece evidente, en especial, en la figura del Conseller.

El debate en torno a la atribución estilística de la obra de Josep Bover se torna, si cabe, todavía más interesante en lo tocante a una obra de principios de la década de 1850, la estatua sedente de Jaume Balmes. Situada encima de una basa también diseñada por el escultor, el conjunto estaba destinado al panteón funerario del filósofo en el cementerio de Vic (provincia de Barcelona), hallándose actualmente en el claustro de la catedral de la misma ciudad. Bover ganó el concurso para la realización de este proyecto, uno de los más largos y complicados en los que se vio inmerso, y

43 Jaume I el Conquistador, mármol, 261 x 118 x 70 cm, 1844 y Joan Fiveller, Conseller II de Barcelona, mármol, 254 x 109 x $70 \mathrm{~cm}, 1846$. Fachada del Ayuntamiento de Barcelona.

${ }^{44}$ Véase, entre otros, GaYA NuÑo, 1958: 98.

45 FontBona, 2009: 42. 
ya estudiado a día de hoy ${ }^{46}$. Judit Subirachs recogió distintas opiniones vertidas al respecto de esta obra, que la sitúan tanto en pleno romanticismo como claro ejemplo de eclecticismo escultórico, mientras que la autora insinuaba que se trataba de una obra realista ${ }^{47}$. A nuestro parecer, esta pieza podría situarse en la línea de evocación romántica que caracteriza la producción madura de Bover. No dista tanto, ni a nivel estilístico ni temático, de las del Ayuntamiento de Barcelona. Balmes representado en actitud contemplativa, reflexivo, con la cabeza ligeramente levantada y con un libro en el regazo. La obra respira mensaje, poesía. Además, ciertas cartas descubiertas a raíz de nuestra investigación permitirían subrayar el contenido nacionalista con el que Bover quería impregnar su trabajo $^{48}$, relacionando así esta obra, al menos en espíritu, con el romanticismo inherente a Jaume I el Conquistador y Joan Fiveller, Conseller II de Barcelona, aunque ahora con más ductilidad y menos arrebato.

Sin lugar a dudas, la década de 1840 dio origen al periodo de madurez de la producción de Josep Bover, iniciando la etapa en la que más encargos y de mayor envergadura gozó el escultor. En este momento se incrementó también su popularidad y proyección pública siendo resultado de ello el aumento de encargos públicos en los que participó. En este sentido, cabe destacar el encargo frustrado para la realización del conjunto heráldico para el ayuntamiento de Barcelona, a principios de la década de 1850, ya estudiado por Judit Subirachs ${ }^{49}$. También debemos señalar su participación en el concurso para la erección de la estatua del rey Pedro IV de Portugal, en $1851^{50}$. Desafortunadamente, la mayor parte de las encomiendas gubernamentales y obras destinadas a espacios públicos de Bover no han sobrevivido al paso del tiempo y son prácticamente desconocidas a día de hoy. Desapareció el escudo de armas de grandes dimensiones que hizo para la fachada principal del antiguo Palacio Real de Barcelona ${ }^{51}$ y también se perdieron los bustos de Lope de Vega, Calderón de la Barca, Manuel García y Vicente Requero que había ideado para la fachada del Teatro de Santa Creu (actualmente, Principal) de la ciudad ${ }^{52}$, que ocupaban la parte central de las columnas adosadas al muro, hoy desnudas. Sin embargo, sí sobrevivieron los trabajos que produjo para la fachada y cornisa de la Capitanía General de Barcelona, un escudo, armas y seis bustos; aunque en las posteriores remodelaciones del edificio se desplazaron los mencionados bustos al interior del edificio ${ }^{53}$.

Un caso distinto y digno de mención es el del Monumento a Isabel II de Palma de Mallorca, un encargo que recibió el escultor en 1860 para conmemorar la reciente visita a la Isla de la pareja real. Se trata de un proyecto completamente desconocido, del que no hemos hallado mención alguna en las fuentes que han tratado la figura de Bover. Sabemos que Bover trabajó las esculturas para el monumento en Carrara y que estaba previsto que él mismo supervisara la colocación de las mismas durante el verano de $1863^{54}$. Este monumento fue destruido al cabo de muy poco tiempo, con motivo de la Revolución de 1868 que precipitó también la caída de la Soberana. Probablemente, el monumento se hallaba en el espacio que antiguamente había ocupado el Convento de los Mínimos de la capital balear.

Muy poco conocidos son también los retratos cortesanos de Josep Bover. Se trata de una faceta de su obra prácticamente inédita y de la que, desafortunadamente, no hemos podido hallar ninguna

46 ViLARó / SEDÓ, 1998: 75-103.

47 Subirachs, 1994: 92.

48 Carta de Josep Bover a la Junta de Comercio, 2 de diciembre de 1851, BNC, Arxiu de la Junta de Comerç, legajo XCII, caja 124, exp. 519.

49 Subirachs, 1994: 111, 198.

${ }^{50}$ El Áncora, 10-III-1851: 1092.

${ }^{51}$ Descripción en Oriol y Bernadet, 1846: 80-81.

${ }^{52}$ El Espectador, 26-V-1846: 4.

53 Millán / Martínez Delgado, 2006: 84

${ }^{54}$ Diario de Menorca, 29-VII-1863: 4. 
imagen fotográfica. Fueron muy elogiados sus retratos del Marqués del Duero, hecho en Madrid en $1851^{55}$, y el del general Prim, Marqués de Castillejos, en $1860^{56}$. A su vez, sabemos que también retrató a los Duques de Montpensier, cuñados de los reyes, a los que conoció en una recepción en Valencia, en la primavera de 1852. Bover trabajó para ellos en el Palacio de San Telmo - su residencia de Sevilla- el verano del año siguiente a su encuentro. Más tarde, los duques le encargaron dos esculturas, un San Luís y un San Fernando, que fueron colocadas en el Palacio en julio de $1857^{57}$.

\section{Carrera docente y ocaso}

Después de varios meses de gestiones, en setiembre de 1829 Bover fue nombrado académico de mérito por la escultura por la Academia de Bellas Artes de San Fernando ${ }^{58}$, como sucedía con muchos de los artistas españoles a la vuelta de su estancia en Roma. De esta época es también su nombramiento por la de San Carlos de Valencia ${ }^{59}$. Estos títulos le beneficiaron en su entrada como profesor, por oposición, en la Escuela de Nobles Artes de Barcelona. Su faceta como docente está aún por explorar, sirva este artículo para exponer algunos datos, inéditos, al respecto. José Bover empezó su labor pedagógica en el curso 1831-1832, a la muerte de su padre, como profesor supernumerario de Dibujo y suplente de Damià Campeny durante sus ausencias o bajas de la clase de Escultura, con un sueldo de 3200 reales de vellón ${ }^{60}$. Se han conservado tanto el reglamento por el que se regía la escuela cuando entró Bover como las bases para las oposiciones de los profesores $^{61}$. La situación contractual del escultor no cambió sustancialmente hasta 1844 , cuando obtuvo el ascenso a Teniente de director y le fue aplicado un aumento de sueldo ${ }^{62}$. Hasta su renuncia al cargo, en 1853, desempeñó su tarea docente en distintas clases, todas vinculadas con el aprendizaje del dibujo. Las hemos podido seguir con exactitud hasta 1841: Flores (1832-33), Sombras (1833$34,1838-39)$, Testas y figuras (1834-35, 1839-40), Perfiles (1835-38) y Elementos de contorno $(1840-41)^{63}$. A partir de la reestructuración de la Escuela que, en octubre de 1849 pasó a depender de la recién creada Academia de Bellas Artes de Barcelona ${ }^{64}$, Bover fue nombrado académico y continuó como profesor de Dibujo de los Estudios menores, centrados en aprendizajes más prácticos destinados a artesanos y operarios de industria. En concreto, se ocupó de la clase de Dibujo de figura hasta principios del curso $1853-54^{65}$.

Durante sus más de veinte años como profesor de la institución, colaboró estrechamente con Damià Campeny, participando en la formación, tanto en el Dibujo como en la Escultura, de varias hornadas de futuros creadores entre los que podemos destacar los escultores Agapit y Venanci Vallmitjana Barbany (1833-1905 y 1826-1919, respectivamente), y Manuel Vilar Roca (1812-1860).

55 El católico, 13-X-1851: 104.

${ }^{56}$ La Iberia, 22-VI-1860: s.p.

${ }^{57}$ La España, 08-VII-1857 (ed. mañana): 1.

58 Actas de Sesiones de la Real Academia de Bellas Artes de San Fernando, 1829, 20-IX-1829, Real Academia de Bellas Artes de San Fernando, RACBASF, fol. 237v. Leticia Azcue recogía las súplicas de Bover a la Academia, con el propósito de dicho nombramiento. Véase Azcue, 2002 (1991): 76.

${ }^{59}$ Véase RACBASJ, caja Junta Comerç. Comunicacions. 1815-1849, mns. 166 y 156.

${ }^{60}$ Nombramiento efectuado el 11 de noviembre de 1831, BNC, Arxiu Junta de Comerç, legajo XCV, n. 6, exp. 187.

${ }^{61}$ Real Junta de Comercio de Cataluña: 1825. BNC, Arxiu Junta de Comerç, legajo CVI, caja 140, n. 2, exp. 78 y 79.

${ }^{62}$ Acuerdo de 31 de agosto de 1844. A 4600 reales de vellón. BNC, Arxiu Junta de Comerç, legajo XCV n. 6, exp. 187 y 172 .

${ }_{63}$ Véase la documentación siguiente (referencias ordenadas cronológicamente): mns.168, 166, 202 y 208, 233, mns. sin numerar: 30-VII-1838, mns. sin numerar 26-IX-1839, mns. 159, mns. sin numerar: 27-IX-1839, mns. s in numerar: 29-IX-1840, RACBASJ, caja Junta Comerç. Comunicacions. 1815-1849. 
Además, viajó regularmente por España e Italia ${ }^{66}$ y fue partícipe de distintas asociaciones, algunas internacionales, como la sección de Artes de la Sociedad del Fomento de la Ilustración, de carácter pedagógico y filantrópico, ó la Asociación Industrial de Oporto, de la que fue corresponsal ${ }^{67}$. Hemos podido descubrir que, al menos durante la década de 1840, Bover tuvo su taller y domicilio particular en la Calle Montserrat de Barcelona ${ }^{68}$, cerca de Drassanes, un dato también inédito. Por otra parte, a lo largo de su carrera como docente, Bover se enfrentó a dificultades y rivalidades profesionales de las que tenemos hoy constancia y que ayudan a perfilar el lado humano del escultor ${ }^{69}$.

El análisis de su somera correspondencia con los organismos supervisores de la Escuela -la Junta de Comercio primero y la Academia más tarde- permite apreciar un deterioro paulatino de su actitud hacia la profesión y sus compañeros de trabajo. Del júbilo fresco y la jovialidad de sus primeras misivas en Roma a las amargas comunicaciones de la década de 1850, se esconde algo más que lo que puede explicarse en razón sólo de la fatiga y desgaste de la edad. Josep Bover renunció definitivamente a su cargo como profesor de la Escuela en setiembre de 1853, después de unos meses sin asistir a las Juntas de la institución ${ }^{70}$. El expediente de renuncia no explica los detalles que le impulsaron a tomar esa decisión, aunque en él el escultor reprocha a la Academia y a sus compañeros el trato dispensado, a su parecer injusto, e indica que se marcha del país ${ }^{71}$. En una misiva escrita desde la población fronteriza de La Junquera, apostilla que espera que en su nueva patria -sin especificar cuál- "no seré tan inhumanamente tratado como lo fuí (sic) de mis compatriotas". A esta resignación contribuyó, sin lugar a dudas, lo sucedido en torno a la ejecución del panteón para la esposa de Vicente de la Busta, un asunto inédito pero esencial para entender los derroteros que tomó la carrera del escultor en sus últimos años ${ }^{72}$. Josep Bover, junto con el arquitecto ecléctico Josep Simó Fontcuberta, fueron los responsables de la creación de dicho panteón, destinado al cementerio del Poblenou de Barcelona y empezado en el verano de 1852. No era el primer panteón que se encargaba al escultor ${ }^{73}$, pero sí fue el más problemático. El proyecto tuvo que modificarse en varias ocasiones conforme a los dictámenes de la Academia de Bellas Artes de la ciudad -principalmente en su parte escultórica-, y se vio interrumpido por la desaparición del escultor, a quien de la Busta y Simó acusaron de engaño y estafa. Este asunto precipitó la salida

${ }^{64}$ Real Orden, 31-X-1849.

${ }^{65}$ RACBASJ, caja 257. COMPTES. Academia Escola 1850-5 y Guía de Forasteros en Madrid, 1852 y 1853.

${ }^{66}$ Hemos podido documentar los siguientes viajes: Tarragona, octubre de 1835 (RACBASJ, caja Junta Comerç. Comunicacions. 1815-1849, mns. 236); Pisa y Carrara, primavera de 1841 (BNC, Arxiu Junta de Comerç, legajo XCIV, caja 126, exp.205); Valencia, primavera de 1852 (El Áncora, 14-IV-1852: 214); Italia, verano de 1852 (RACBASJ, legajo 20, caja 20, exp.29); Sevilla y Madrid, primavera - verano de 1853 (Real Orden, 20-I-1853).

${ }^{67}$ El Guarda Nacional, 26-V-1840: 3. El Áncora, 14-V-1853: 716.

${ }^{68}$ Hemos hallado dos direcciones en la misma calle Montserrat, correspondientes a los números 14 y 8 . BNC, Arxiu de la Junta de Comerç, legajo XCV, caja 127, n. 6, exp.305 y legajo CV, caja 139, n.4, exp. 38-40.

${ }_{69}$ Por ejemplo, el enfrentamiento con el profesor Josep Corominas (RACBASJ, caja Junta Comerç. Comunicacions. 1815-1849, mns. 177) ó los retrasos en la entrega de las obras que anualmente debía depositar en la Escuela (RACBASJ, caja Junta Comerç. Comunicacions. 1815-1849, mns. 247).

${ }^{70} \mathrm{La}$ última de las Juntas a las que asistió tuvo lugar el 26 de enero de 1852. Véase RACBASJ, libro 19. Acuerdos sobre la Junta Gral de profesores. Desde 27 de octubre 1850 a 19 diciembre 1861.

${ }^{71}$ Bover dice haber tenido que soportar "los sarcasmos de la ignorancia" y encontrarse "mendigando el pan de la penuria". Véase Expediente sobre renuncia del cargo de profesor de estudios menores y de figura D. José Bovér, RACBASJ, caja 2. Acadèmia de BBAA. Documents sobre Acadèmies. Escola, exp. 25.

${ }_{72}$ RACBASJ, legajo 20, exp. 29. La información sobre el proyecto que se explica a continuación procede de este expediente.

${ }^{73}$ Antes de 1849, Bover habría esculpido un conjunto decorativo para el panteón de Pablo Torrens i Miralba, encargo de su viuda Carmen Casademunt, también para el cementerio del Poblenou en Barcelona. SAURí/Matas, 1849: 127.

Arch. esp. arte, LXXXVI, 344, octUBRE-DICIEMBRE 2013, 331-344, ISSN: 0004-0428 
de Bover de Barcelona, así como el cese de sus actividades en la Escuela y en el seno de la Academia. Su vacante fue ocupada de forma interina por el pintor Ramon Martí i Alsina.

Durante los años siguientes, Josep Bover se dedicó básicamente a encargos particulares, algunos de los cuales ya hemos referido en este artículo. De esta última época, destacan, además, los trabajos que realizó en Cádiz, donde suponemos estableció su taller en torno a 1856, aunque en 1860 habría ya regresado a Barcelona ${ }^{74}$. Suyas son las estatuas de Santa Clara y San Fernando en mármol que ocupan las hornacinas laterales de la Capilla de Santo Tomás de Villanueva de la Catedral de la ciudad andaluza. Desde Cádiz dirigió Bover la última de las cartas a la Academia barcelonesa de las que tenemos constancia, en la que rogaba se diera permiso a su hermano, Salvador Bover, para gestionar el vaciado en yeso del Gladiador herido, cara a un trabajo que estaba ejecutando destinado a ser expuesto en Londres el año siguiente. En ella también se pedía que fuera Aquiles Nicoli, profesor de la Escuela Menor de Barcelona, quien realizara tal tarea ${ }^{75}$. No hemos podido hallar ninguna pista de a qué exposición londinense de 1857 fue destinado el vaciado, ni si este llegó a realizarse, aunque sí sabemos que Salvador Bover remitió dos yesos -entre los que había una copia del Gladiador-, a la Exposición Internacional de Londres de 1862, un envío tramitado por la Academia ${ }^{76}$. Probablemente, las piezas no fueron retenidas por el jurado, puesto que no aparecen en el catálogo de la muestra ${ }^{77}$.

Josep Bover i Mas murió en Barcelona en agosto de $1866^{78}$. Tras de sí quedaban más de cuarenta años dedicados a la profesión, y cerca de veinte de labor docente. Este artículo ha pretendido profundizar en la significación e importancia estratégica de este autor cuya memoria se ha mantenido a la sombra de escultores como Damià Campeny o Antoni Solà, como sucede con tantos otros de su generación y orígenes. El conocimiento de la figura de Josep Bover contribuye a mejorar la comprensión que de la escultura española del momento disponemos y permite, a su vez, revisar la afiliación global de su producción al academicismo, sugiriendo, para terminar, la conveniencia de examinar bajo perspectivas renovadas las producciones de muchos de nuestros escultores decimonónicos.

\section{BIBLIOGRAFÍA}

Alonso Sánchez, María Angeles, "El primer reglamento de pensionados de la Academia de Bellas Artes en Roma", Cuadernos de prehistoria y arqueología, n. 3, 1976, pp. 91-102.

Azcue, Leticia, El museo de la Real Academia de Bellas Artes de San Fernando: la escultura y la Academia, Tesis doctoral dirigida por José María Azcárate, Universidad Complutense de Madrid, 2002, 1991.

Benet, Rafel, L'Art català, vol. II, Barcelona, Aymà, 1958.

Cid, Carlos, et al., La vida y la obra del escultor neoclásico catalán Damià Campeny i Estrany, Barcelona, Biblioteca de Catalunya / Caixa Laietana, 1998.

Dotal, Christiane, "Paris-Rome-Madrid : l'influence de l'art français et romain sur les sculpteurs espagnols dans la première moitié du XIX es siècle", Mélanges de la Casa de Velázquez, 18-X-2010, n.36-2 [En línea] http://mcv.revues.org/2497.

\footnotetext{
${ }^{74}$ La Iberia, 1-VIII-1860: 3.

75 RACBASJ, caja 23. Acadèmia de Belles Arts. Sección de Escultura. Dictámenes 1850-1870, exp. 105. Véase también nota 30 del presente artículo.

${ }^{76}$ BNC, Arxiu Junta de Comerç, legajo CXXVIII, caja 166, n. 2, exp. 186.

77 Véase Official Catalogue, 1862: 241-244.

${ }^{78}$ La época, 27-III-1867: 1. La Correspondencia de España. Diario Universal de noticias, 28-VIII-1866: 2.
} 
Elias de Molins, Antonio, Diccionario biográfico y bibliográfico de escritores y artistas catalanes del siglo $X I X$ : apuntes y datos, Barcelona, Imprenta de Fidel Giró e Imprenta de Calzada, 1889-1895.

Elias, Feliu, L'escultura catalana moderna. Volum II: Els artistes, Barcelona, Barcino, 1928.

Fontbona, Francesc, Història de l'Art Català. Volum 4: Del Neoclasicisme a la Restauració: 1808-1888, Barcelona, Edicions 62, 1983.

García Portugués, Esther, José Nicolás de Azara i la seva repercussió en l'àmbit artístic català, Tesis doctoral dirigida por Rosa Ma Subirana, Universidad de Barcelona, 2007.

Gaya Nuño, Juan Antonio, “Arte del siglo XIX”, en Ars Hispaniae. Historia Universal del Arte Hispánico, vol. XIX, Madrid, Plus Ultra, 1958.

Madoz, Pascual, Diccionario geográfico-estadístico-histórico de España y sus posesiones de ultramar, Tomo III, Madrid, Establecimiento tipográfico de P. Madoz y L. Sagasti, 1846-1850.

Millán Rubio, Joaquín; Martínez Delgado, Pablo, El Palau de Capitania General de Barcelona, Barcelona, Generalitat de Catalunya, 2006.

Official Catalogue of the Fine Art Departament. International Exhibition. London 1862, Londres, Truscot, Son \& Simmons, 1862.

Oriol y Bernadet, "Obras de escultura”, en Boletín Enciclopédico de Nobles Artes, 1-VI-1846, tomo I, n.5, p. $80-81$.

Pardo Canalís, Enrique, Escultura neoclásica española, Madrid, Instituto Diego Velázquez, CSIC, 1958.

Ràfols, Joan Francesc, Diccionario Biográfico de artistas de Cataluña, vol. I, Barcelona, Millà, 1951.

Real Junta de Comercio de Cataluña, Catálogo de las obras de escultura que existen en el Museo de la Junta de Comercio de Cataluña, Barcelona, J. Ferrando Roca, 1847.

Real Junta de Comercio de Cataluña, Reglamento para el regimen interior de la escuela Gratuita de Nobles Artes establecida en la ciudad de Barcelona á expensas de la Real Junta de Comercio de Cataluña, dispuesto y mandado observar por la misma, Barcelona, Viuda de Agustin Roca, 1825.

Riera, Anna, La Formació dels escultors catalans : l'ensenyament de l'Escola Gratuïta de Dibuix $i$ els pensionats a Madrid i Roma, 1775-1815, tesis doctoral dirigida por Joan Ramon Triadó, Universidad de Barcelona, 1994.

Saurí, Manuel; Matas, José, Manual histórico-topográfico, estadístico y administrativo : ó sea guía general de Barcelona, Barcelona, Imprenta y librería de Manuel Saurí, 1849.

Subirachs, Judith, L'escultura del segle XIx a Catalunya, Barcelona, Publicacions de l'Abadia de Montserrat, 1994.

Varios autores, Art Públic de Barcelona, 2009.

Vélez, Pilar, Catàleg del museu de Llotja : Reial Acadèmia Catalana de Belles Arts de Sant Jordi, Barcelona, Reial Acadèmia Catalana de Belles Arts de Sant Jordi, 2001.

Vilaró i Comas, Silvia; Sedó i Galí, Adam, "Del Cementiri Municipal al Claustre Gòtic. El monument commemoratiu a Jaume Balmes", Ausa, 1998, n. 140-141, vol. 18, pp. 75-103.

http://www.gencat.cat/drep/dgri/sumaris/llibre_capitania.pdf

Fecha de recepción: 8-V-2012

Fecha de aceptación: 9-VII-2012

Arch. esp. arte, LXXXVI, 344, octUBRE-DICIEMBRE 2013, 331-344, ISSN: 0004-0428 